\title{
Potentially toxic trace element pollution in long-term fertilized agricultural soils in China: A meta-analysis
}

\author{
Shiwei Zhou ${ }^{a}$, Shu Su ${ }^{b}$, Ling Meng ${ }^{c}$, Xiao Liu ${ }^{a}$, Hongyuan Zhang ${ }^{\text {a }}$, Xiaoli Bi ${ }^{\mathrm{c}, *}$ \\ a School of Agriculture, Ludong University, Yantai 264025, Shandong, China \\ b College of Agriculture, Guizhou University, Guiyang 550025, Guizhou, China \\ c Yantai Institute of Costal Zone Research, Chinese Academy of Sciences, Yantai 264003, Shandong, China
}

\section{H I G H L I G H T S}

- Long-term organic fertilization increased the relative availability of $\mathrm{Zn}$ by $96-128.6 \%$

- Cd pollution in organic fertilized croplands (approximately one-half) is the most important issue

- Type and application rate of organic fertilizers and soil type were dominant factors influencing variation of PTTEs

- Organic fertilizers containing Cd less than $1 \mathrm{mg} \mathrm{kg}^{-1}$ were recommended

- Lower amounts of P fertilizers were proposed for Alfisols and Semihydromorphic soils

\section{A R T I C L E I N F O}

\section{Article history:}

Received 17 March 2021

Received in revised form 13 May 2021

Accepted 19 May 2021

Available online 24 May 2021

Editor: Filip M.G. Tack

\section{Keywords:}

Cadmium

Manure

P fertilizer

Meta-analysis

Effect size

Soil available potentially toxic trace elements
GRA PHICA L A B S T R A C T

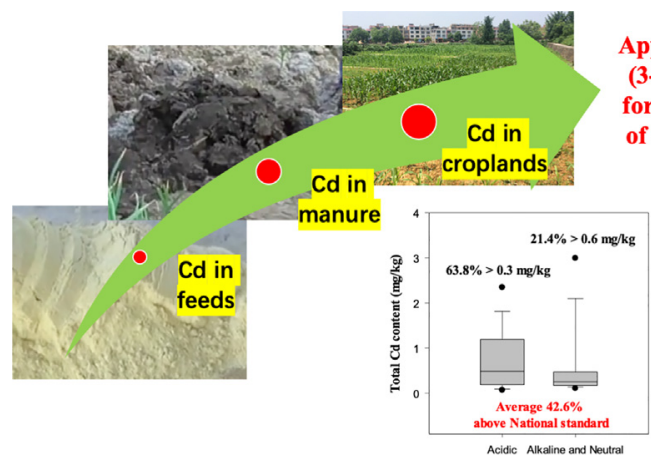

Applying organic fertilizers

(3-35 years) is responsible

for approximately one-half

of $\mathrm{Cd}$ pollution in Chinese croplands

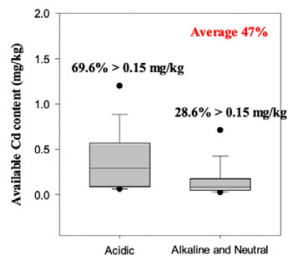

\begin{abstract}
A B S T R A C T
Fertilization results in potentially toxic trace element (PTTE) pollution in agricultural soils. However, it is unclear which factors determine the effect sizes of fertilization on PTTEs at the multiple spatial-temporal scale. This work synthesized 379 observations in 78 field sites (3-35 years) across China's main grain producing areas, and showed that long-term organic fertilization significantly enhanced total $\mathrm{Cu}, \mathrm{Zn}$ and $\mathrm{Cd}$ by $25.7 \%, 18.9 \%$ and $66.6 \%$, and soil available $\mathrm{Cu}, \mathrm{Zn}$ and $\mathrm{Cd}$ by $60.5 \%, 155.3 \%$ and $83.6 \%$, respectively; whereas long-term inorganic fertilization increased only available $\mathrm{Cu}, \mathrm{Zn}$ and $\mathrm{Cd}$ by an average of $6.3 \%$. Organic fertilizer (OF) type and application rate dominated the variation of PTTE concentrations, where approximately one-half of $\mathrm{Cd}$ pollution (42.6\% of total $\mathrm{Cd}$ and $47 \%$ of available $\mathrm{Cd}$ ) was observed. Furthermore, OFs containing $\mathrm{Cd}$ less than $1 \mathrm{mg} \mathrm{kg}^{-1}$ were recommended to be safely applied to agricultural soils. Soil type was main factor under long-term inorganic fertilization determining available PTTE variation, resulted in higher pollution risk in some soils such as Alfisols and Semihydromorphic soils, where we suggested the use of lower amounts of P fertilizers or the application of ones having small amounts of PTTEs. In short, long-term organic fertilization caused serious pollution of PTTEs especially $\mathrm{Cd}$ in Chinese croplands, and some strategies with a focus towards reducing the pollution risk must be developed, e.g., promoting straw return, forbidding $\mathrm{Cd}$ addition to feeds and feed additives, and improving carbon sequestration efficiency (CSE) of OFs and thus soil organic matter (SOM).
\end{abstract}

(c) 2021 Elsevier B.V. All rights reserved.

\footnotetext{
* Corresponding author.

E-mail address: xlbi@yic.ac.cn (X. Bi).
}

\section{Introduction}

Fertilizer plays an important role in increasing cereal yields, the global use of which has increased by $30.8 \%(\mathrm{~N}), 31.4 \%\left(\mathrm{P}_{2} \mathrm{O}_{5}\right)$ and 
$61.3 \%\left(\mathrm{~K}_{2} \mathrm{O}\right)$, respectively, from 2002 to 2017 (FAOSTAT, 2020). For the next 30 years, more fertilizers would be used to obtain more products to feed the projected global population of over 9 billion (Godfray et al., 2010; Thompson, 2016). However, their excessive use caused farmland pollution due to a large input of potentially toxic trace elements (PTTEs) from fertilizers (Mortvedt, 1995; Atafar et al., 2010; Ramos et al., 2020).

Most researchers in America and Europe have generally accepted that application of inorganic phosphate fertilizers has inadvertently added Cd and other toxic elements to the soil (Mortvedt, 1995; Nziguheba and Smolders, 2008; Atafar et al., 2010). For example, even only 2-year-period of fertilization could result in PTTE concentration increasing 1.1-2.9 times after harvesting (Atafar et al., 2010). In China its application, even at very high levels $\left(100-120 \mathrm{~kg} \mathrm{P}_{2} \mathrm{O}_{5} / \mathrm{ha}\right)$, has insignificantly increased the soil total PTTE contents (Zhou et al., 2015; Rao et al., 2018). However, it is still necessary to regulate the utilization of phosphate fertilizers in North China, especially in Henan, due to having the highest $\mathrm{Cd}$ input from phosphate fertilizers, also due to the increase in the content of bioavailable soil Cd after phosphate fertilizer application, which causes a higher content of $\mathrm{Cd}$ in agricultural products (Dharma-Wardana, 2018; Li et al., 2020). It is known that the risk of $\mathrm{Cd}$ accumulation by crops is more related to its availability than the total Cd present in the soil, therefore, more efforts should be put to evaluate the effect of long-term phosphate fertilization on available $\mathrm{Cd}$ levels in soils. Yet, only a limited number of studies have focused on it (Rao et al., 2018; Wei et al., 2020), and there is a big knowledge gap in understanding which factors have the greatest effect on availability.

A large number of studies on the influence of organic fertilization have been published, and most have only focused on high inputs of PTTEs and the subsequent pollution from animal manure, without paying attention to availability with long-term manure application (Luo et al., 2009). Both soil organic matter (SOM) and dissolved organic matter (DOM) increased markedly after long-term organic fertilization, where SOM could immobilize PTTEs and reduce their bioavailability; while DOM could enhance the mobilization of PTTEs from soil (Antoniadis and Alloway, 2002; Karlsson et al., 2006; Ondrasek and Rengel, 2012; Laurent et al., 2020). Thus, it is still unclear whether the availability increases or decreases. Additionally, there are many kinds of organic fertilizers (OFs) with different content of PTTEs that could be used in farmland, resulting in considerable variations in accumulation in these PTTEs in soil. It is also unclear which fertilizer should be preferred for environment safety. For example, swine manure was frequently considered as a primary contributor of PTTEs especially $\mathrm{Cu}$ and Zn to farmland (Novak et al., 2004; Shi et al., 2011; Liu et al., 2020). However, our previous study showed only the content of Cd in long-term swine manure-fertilized soils exceeded (by 3 -fold) the national standard (Zhou et al., 2015). Similar results indicated swine and chicken manures were mainly responsible for Cd contamination of farmland soils (Li et al., 2010). Also, some studies showed that total soil $\mathrm{Cu}$ and $\mathrm{Zn}$ concentrations, as well as available soil $\mathrm{Cd}$ and $\mathrm{Zn}$ concentrations, were elevated significantly due to the long-term application of higher rates of cattle manure (Benke et al., 2008), which supply about $64 \%$ of total Cd inputs in soils in England and Wales (Nicholson et al., 2003).

Soil, crop, fertilizer, and climate all influenced the load, distribution, accumulation, and availability of PTTEs in soil-plant systems (Hou et al., 2017; Zupancic, 2017). We need a better understanding of what drives these variations of PTTE contents in agricultural soil, in order to both improve fertilizer efficiency and reduce environmental pollution. Soil PTTE pollution derived from fertilizer use is a slow process occurring over decades, which can be described only by relying on long-term field experiments. However, there is a lack of studies conducted to determine effect size of fertilization at multiple spatial-temporal scales. In this study, we conducted a synthesis of 379 experimental observations in 78 field sites in 22 provinces across China's main grain producing areas, which represented the typical farming systems in this country (Fig. S1 and Dataset 1). The questions we addressed were (1) Which element is the most strongly associated with fertilizer application among $\mathrm{Cu}, \mathrm{Zn}, \mathrm{Cd}$, and $\mathrm{Pb}$ ? (2) Which variable affects the heterogeneity of soil PTTEs the most? (3) If so, what measures can be taken to minimize environmental pollution caused by fertilizer overuse?

\section{Materials and methods}

\subsection{Sampling and chemical analysis}

After the autumn harvest (2012-2014), soil samples were collected from the $0-20 \mathrm{~cm}$ soil layer at each experiment plots from 39 long-term fertilization sites across China (Fig. S1 and Dataset 1 ). The fresh soil samples were air-dried and ground to pass through a $1 \mathrm{~mm}$ sieve for the determination of available $\mathrm{Cu}, \mathrm{Zn}, \mathrm{Cd}$ and $\mathrm{Pb}$, and a $0.15 \mathrm{~mm}$ sieve for the analysis of their respective total content. Animal manure, green manure, and straw were also collected from some of the above sites. After collection, they were oven-dried at $70{ }^{\circ} \mathrm{C}$, ground and passed through a $0.25 \mathrm{~mm}$ sieve for the determination of total metal concentrations.

Available PTTEs in acidic soils were extracted with $0.1 \mathrm{M} \mathrm{HCl}$; while those in neutral and alkaline soils were extracted with $0.005 \mathrm{M}$ diethylenetriaminepentaacetic acid (DTPA) in $0.01 \mathrm{M} \mathrm{CaCa}_{2}$, buffered at $\mathrm{pH} 7.3$ with $0.1 \mathrm{M}$ triethanolamine (TEA) (Lindsay and Norvell, 1978; Qian et al., 1996). The detailed procedures were as follows: $5.00 \mathrm{~g}$ air-dried soil passed through a $1 \mathrm{~mm}$ sieve was mixed with $25 \mathrm{~mL}$ DTPA (or $\mathrm{HCl}$ ) and continuously stirred at $25^{\circ} \mathrm{C}$ for $2 \mathrm{~h}$. The suspension was centrifugated at $4500 \mathrm{rpm}$ for $10 \mathrm{~min}$ and kept at $4{ }^{\circ} \mathrm{C}$ for subsequent determination. To measure the contents of PTTEs in soil, manure and straw, soil samples were digested by $\mathrm{HNO}_{3}-\mathrm{HF}$, and manure and straw samples were digested by $\mathrm{HNO}_{3}$ in microwave (Wu et al., 1997; Sandroni et al., 2003). The detailed procedures were as follows: air-dried soil $(0.5000 \mathrm{~g})$ passed through a $0.15 \mathrm{~mm}$ sieve was weighted in a digestion vessel, into which $3 \mathrm{~mL} \mathrm{HF}$ and $9 \mathrm{~mL} \mathrm{HNO}_{3}$ were added and allowed to stand for $24 \mathrm{~h}$ at room temperature, then digested in a microwave digester (Anton Paar Multiwave 3000, Graz, Austria), following a gradient temperature program: from ambience to $120^{\circ} \mathrm{C}$ (increasing at the rate of $20^{\circ} \mathrm{C} \mathrm{min}{ }^{-1}$ ), then $120{ }^{\circ} \mathrm{C}$ for $3 \mathrm{~min}$, and then $7{ }^{\circ} \mathrm{C} \mathrm{min}^{-1}$ to $190{ }^{\circ} \mathrm{C}$, followed by a final hold at $190{ }^{\circ} \mathrm{C}$ for $20 \mathrm{~min}$. The digested sample was transferred into Teflon crucible and then heated on an electric hot plate to drive away the acids. Finally, it was diluted with $0.5 \% \mathrm{HNO}_{3}$ to $25 \mathrm{~mL}$, filtrated and stored at $4{ }^{\circ} \mathrm{C}$ for later analysis. All digestion and extraction solutions were finally analyzed for $\mathrm{Cu}, \mathrm{Zn}$, and $\mathrm{Pb}$ by inductively coupled plasma optical emission spectrometry (ICP-OES, Varian 715-ES, Varian Medical Systems, USA), and for Cd by atomic absorption spectrometry (AAS, ZEEnit 700, Analytik Jena AG, Germany). For each sample, three repetitions were performed, and the results were presented as means \pm SD.

In addition, several reference soil and plant samples (GBW07451 and GBW07449 for soil digestion; GBW07458, GBW07416a and GBW07413a for soil extraction; GBW07603 for manure and straw digestion) and reagent blanks were used as the quality control samples during the analyses, where total $\mathrm{Cu}, \mathrm{Zn}, \mathrm{Cd}, \mathrm{Pb}$ recoveries were $101.9 \%$, 98.7\%, 98.2\%, and 95.3\%; whereas available PTTE recoveries were $105.9 \%, 95.0 \%, 100.9 \%$, and $97.6 \%$, respectively. Analytic reagents purchased from Sinopham Chemical Reagent Co., China, and ultra-pure water $(18 \mathrm{M} \Omega \cdot \mathrm{cm})$ supplied from Pall Co., USA, were used throughout the whole experiments.

\subsection{Data collection and dataset construction}

An extensive literature survey was conducted through China National Knowledge Infrastructure (CNKI), China Wanfang Database, China Weipu Database, National library of China, Web of Science, and Google Scholar until June 30, 2019. The search keywords were ("longterm fertilization" OR "long-term fertilizer" OR "long-term experiment") AND ("heavy metal" OR "microelement" OR "trace element"). The following criteria were used to select appropriate studies: (1) only 
those long-term fertilization field experiments located in China were selected; (2) field experiments were conducted for not less than 3 years; (3) for each treatment, total and available contents of at least one of these potentially toxic trace elements $(\mathrm{Cu}, \mathrm{Zn}, \mathrm{Pb}$ and $\mathrm{Cd})$ were determined; (4) experiments were designed to include a control group (no fertilization) and one or more treatment group (inorganic and/or organic fertilization); (5) OFs used for the experiments are animal manure, green manure, straw, and their compost, but not including sewage sludge; (6) only the results from the last sampling period were collected if multiple measurements were performed throughout the experimental period in the same study site, because meta-analysis required that datasets are independent (Hedges et al., 1999). Using these criteria, 28 studies at 39 experimental sites were found to be suitable for the meta-analysis (Fig. S1, Reference list and Dataset 1).

The data were directly gathered from tables and from figures by the GetData Graph Digitizer (Version 2.26.0.20, Russia). If only standard error (SE) was provided, it was converted to SD: $S D=S E \sqrt{n}$ ( $n$ is the sample size). In the cases where no SD or SE were reported, 1/10 of means was determined as SD (Luo et al., 2006).

As a result, this dataset included data measured by ourselves (39 sites) as well as data collected through a literature survey (39 sites). That is, a total of 379 paired observations covering 78 experimental sites were included in this study, which was divided into $\mathrm{Cu}$ (231 observations), Zn (233 observations), Cd (207 observations) and $\mathrm{Pb}$ (207 observations) in inorganic fertilization treatments, $\mathrm{Cu}$ (311 observations), Zn (315 observations), $\mathrm{Cd}$ (275 observations) and $\mathrm{Pb}$ (274 observations) in organic fertilization treatments (Dataset 1 ).

The dataset also included location (i.e., latitude and longitude) and climate factors (mean annual temperature (MAT), mean annual precipitation (MAP), annual evaporation, $\geq 10{ }^{\circ} \mathrm{C}$ accumulated temperature, and aridity index (AI)), initial soil factors (soil type, parent material, texture, $\mathrm{pH}$, SOM, Olsen-P, available $\mathrm{N}$ and $\mathrm{K}$ ), cultivation factors (crop type, cultivated land type, rotation, multi-cropping), and fertilization factors (OF type, OF application rate, PTTE content in OFs, inorganic $P$ fertilization) in each site. Overall, the dataset covered broad variations in climate, soil, cultivation and fertilization. All data except those measured by ourselves were extracted from 52 publications (Dataset 1 and Reference list).

\subsection{Meta-analysis}

Effect sizes of fertilization on total and available potentially toxic trace element concentrations in soils were expressed as the natural $\log$-transformed response ratio $(\ln (\mathrm{RR}))$, and were calculated by Eq. (1):

$\ln (\mathrm{RR})=\ln \left(\frac{\overline{\mathrm{X}_{\mathrm{t}}}}{\overline{\overline{\mathrm{X}_{\mathrm{c}}}}}\right)$

where $\overline{\mathrm{x}_{\mathrm{t}}}$ and $\overline{\mathrm{x}_{\mathrm{c}}}$ are the means of treatment (with fertilizer application) and control (without fertilizer application), respectively.

Variance (Var) of $\ln (\mathrm{RR})$ was computed by Eq. (2):

$\operatorname{Var}(\operatorname{lnRR})=\frac{\mathrm{SD}_{\mathrm{t}}^{2}}{\mathrm{n}_{\mathrm{t}} \overline{\mathrm{x}_{\mathrm{t}}^{2}}}+\frac{\mathrm{SD}_{\mathrm{c}}^{2}}{\mathrm{n}_{\mathrm{c}} \overline{\mathrm{X}_{\mathrm{c}}^{2}}}$

where $n_{t}$ and $n_{c}$ were the sample size of the treatment and control groups, respectively; $\mathrm{SD}_{\mathrm{t}}$ and $\mathrm{SD}_{\mathrm{c}}$ were the $\mathrm{SDs}$ of the treatment and control groups, respectively (Luo et al., 2006).

$\ln (\mathrm{RR})$ was used as an effect size metric for the meta-analysis. The use of the natural logarithm linearizes the metric, ensuring the approximate normal distribution with a mean equal to the true response ratio (Luo et al., 2006; Seufert et al., 2012). For interpretation of the results, mean effects and 95\% confidence intervals (CI) were backtransformed, using the formula: $\left(\mathrm{e}^{\ln (\mathrm{RR})}-1\right) \times 100 \%$ and reported as the percentage changes between control and fertilizer application. A significant response could be considered if its 95\% CI did not overlap zero (Seufert et al., 2012).

Due to the higher heterogeneities among the subgroups, observations with the same or similar management or system characteristics were grouped together (Table S1), and the grouped effects were computed using a categorical meta-analysis with a random model (MetaWin 2.1, Sinauer Associates Inc., USA). To test for differences in the effect sizes between groups, the total heterogeneity of the sample was partitioned into the within group $\left(\mathrm{Q}_{W}\right)$ and between group heterogeneity $\left(\mathrm{Q}_{\mathrm{B}}\right)$, and the significance of $\mathrm{Q}_{\mathrm{B}}$ was tested by comparing it against the critical value of the $\chi^{2}$ distribution. A significant $\mathrm{Q}_{\mathrm{B}}(p<$ 0.05 ) indicated that there are differences among cumulative effect sizes between groups, so, only those effects showing a significant $Q_{B}$ are presented in graphs (Seufert et al., 2012). Moreover, all of these variables with significant $Q_{B}$ were selected and combined for multivariable meta-regression analysis, so as to determine dominant factors controlling soil PTTE variation under long-term fertilization. Stata/SE 15.0 (Stata Corp., College Station, TX, USA) was used to build a regression model through analysis of the influence of the $t$-value and $p$-value to determine heterogeneity of variables, where statistical significance was assumed at $p<0.05$ (Thompson and Higgins, 2002; Yu et al., 2018).

\section{Results}

3.1. Overall effects of long-term fertilization on total and available potentially toxic trace element content

Long-term organic fertilization increased total $\mathrm{Cu}, \mathrm{Zn}$ and $\mathrm{Cd}$ by 25.7\% (21.4-30.0\%), 18.9\% (16.0-21.8\%) and 66.6\% (52.7-80.5\%) and soil available $\mathrm{Cu}, \mathrm{Zn}$ and $\mathrm{Cd}$ by $60.5 \%$ (50.1-70.9\%), $155.3 \%$ (128.2-182.4\%) and 83.6\% (62.5-104.6\%), respectively; whereas longterm inorganic fertilization increased only available $\mathrm{Cu}, \mathrm{Zn}$ and $\mathrm{Cd}$ by an average of 6.3\% (Fig. 1). There was no difference in $\mathrm{Pb}$ content and availability between fertilization (whether inorganic or organic) and control (without fertilizer application).

From Fig. 1 it could be seen that organic fertilization caused much higher risk of PTTE pollution than inorganic fertilization, where the biggest concern would be the highest increase in soil total $\mathrm{Cd}$ and available Zn. Generally, a more significant increase in available metal amounts in fertilized soils was observed. For this reason, relative availability (RA) as the ratio of available PTTE (DTPA or $\mathrm{HCl}$ ) to total PTTE concentration was calculated and shown in Fig. S2 (Inaba and Takenaka, 2005; Karalić et al., 2013; Ouyang et al., 2020), which demonstrated that OF application resulted in the highest increase in $\mathrm{RA}_{\mathrm{Zn}}(96.0-128.6 \%)$, and the smallest increase in $\mathrm{RA}_{\mathrm{Cd}}$ (4.5-15.8\%). Because using $\mathrm{RA}$ as an indicator may minimize measurement errors among different researchers, compared to an absolute value (total or available metal content) ( $\mathrm{Su}$ et al., 2015); more importantly, RA made it possible to compare PTTE availability from different extraction procedures such as HCl-, DTPA-, and DGT-extractability, and Exchangeable forms (Su et al., 2015; Dataset 1), it is clear that RA is a better indicator of risk of PTTE pollution than those total and available fractions.

\subsection{Dominant factors determining the variation in soil PTTEs under long- term OF application}

The content and availability of PTTEs in organically fertilized soils were controlled by many soil, climate and fertilization factors such as soil type, texture and parent material, site location, OF type and application rate (Tables S2-S3, Figs. S3-S4). However, multivariate metaregression model confirmed that $\mathrm{OF}$ type and application rate (equivalent $C$ input) appeared to be the most important factors, where OF type mainly determined the variation of total and available $\mathrm{Cu}$ and $\mathrm{Zn}$, with variation explained $\left(\mathrm{R}^{2}\right)$ being $21.66 \%$ and $19.91 \%$ for total $\mathrm{Cu}$ and $\mathrm{Zn}$, $26.96 \%$ and $16.72 \%$ for available $\mathrm{Cu}$ and $\mathrm{Zn}$, respectively; while soil $\mathrm{Cd}$ 
(A) Inorganic fertilization
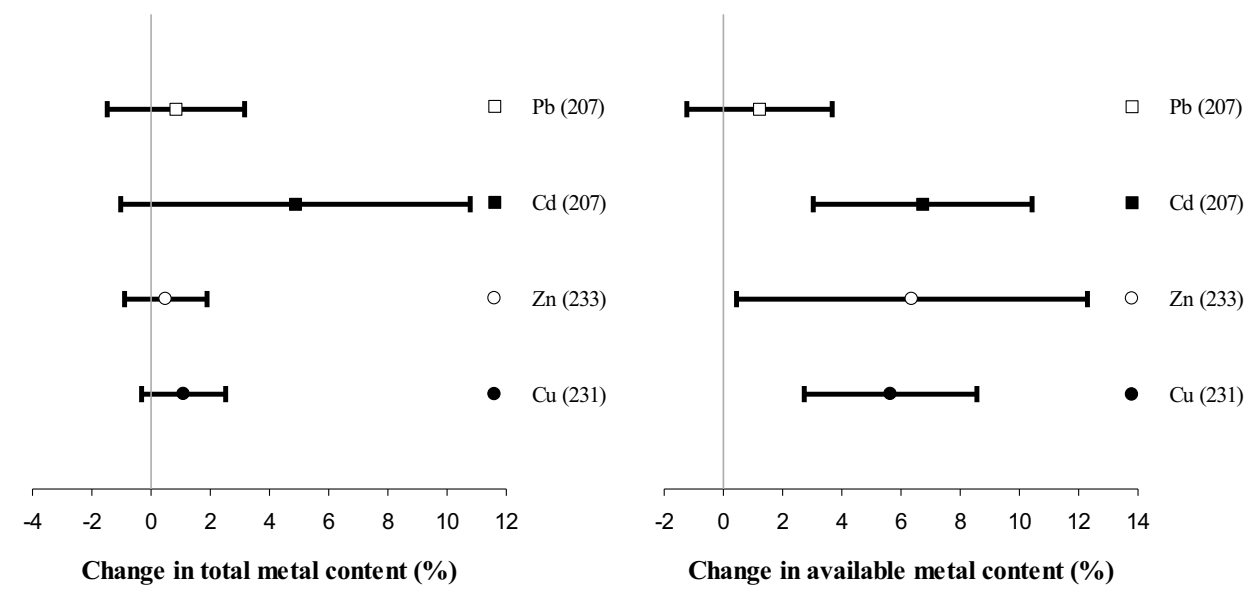

(B) Organic fertilization

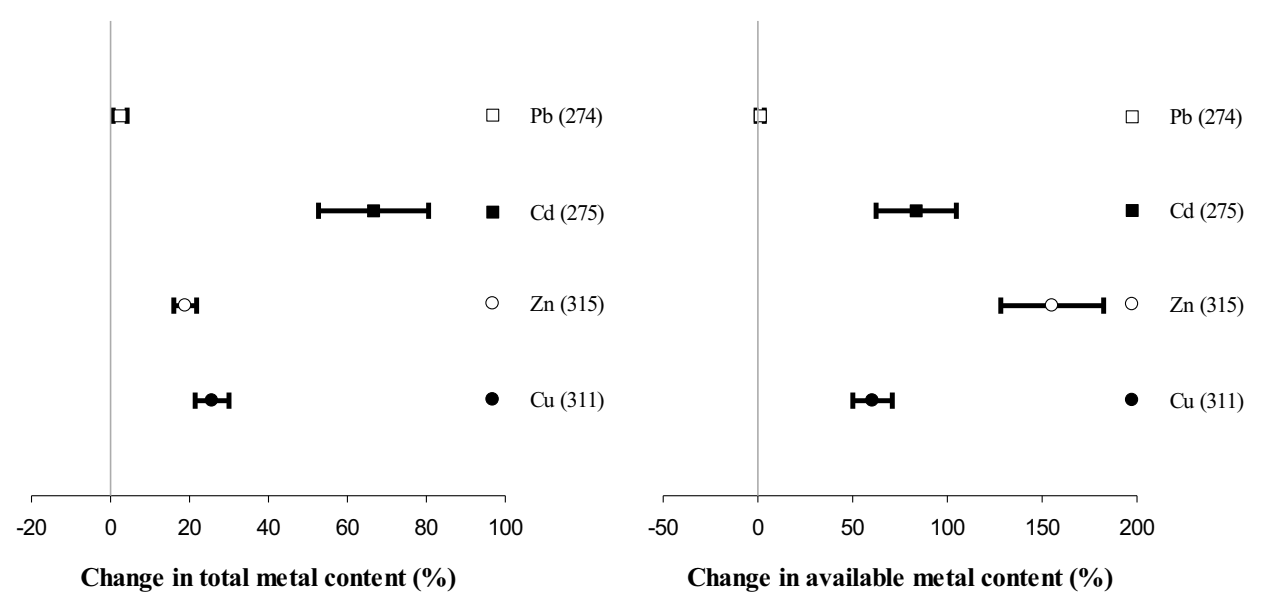

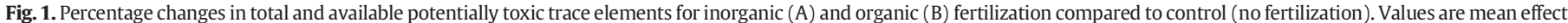
sizes with $95 \%$ confidence intervals $(\mathrm{CI})$. A significant response is when $\mathrm{CI}$ does not overlap 0 . The number of observations in each class is shown in parentheses.

was dominantly determined by OF application rate, with $\mathrm{R}^{2}=16.07 \%$ and $14.88 \%$ for total and available Cd, respectively (Tables S4-S9).

OF type exhibited a higher effect on the accumulation of PTTEs comparing to its application rate (Fig. 2), where swine manure and high application rate of other animal manure significantly enhanced the accumulation of $\mathrm{Cd}$ (by $508.8 \%$ ), $\mathrm{Zn}$ (by $53.4 \%$ ) and $\mathrm{Cu}$ (by $84.7 \%$ ) in soils (3-7 times higher than average); whereas long-term application of straw and green manure did not increase soil PTTEs.
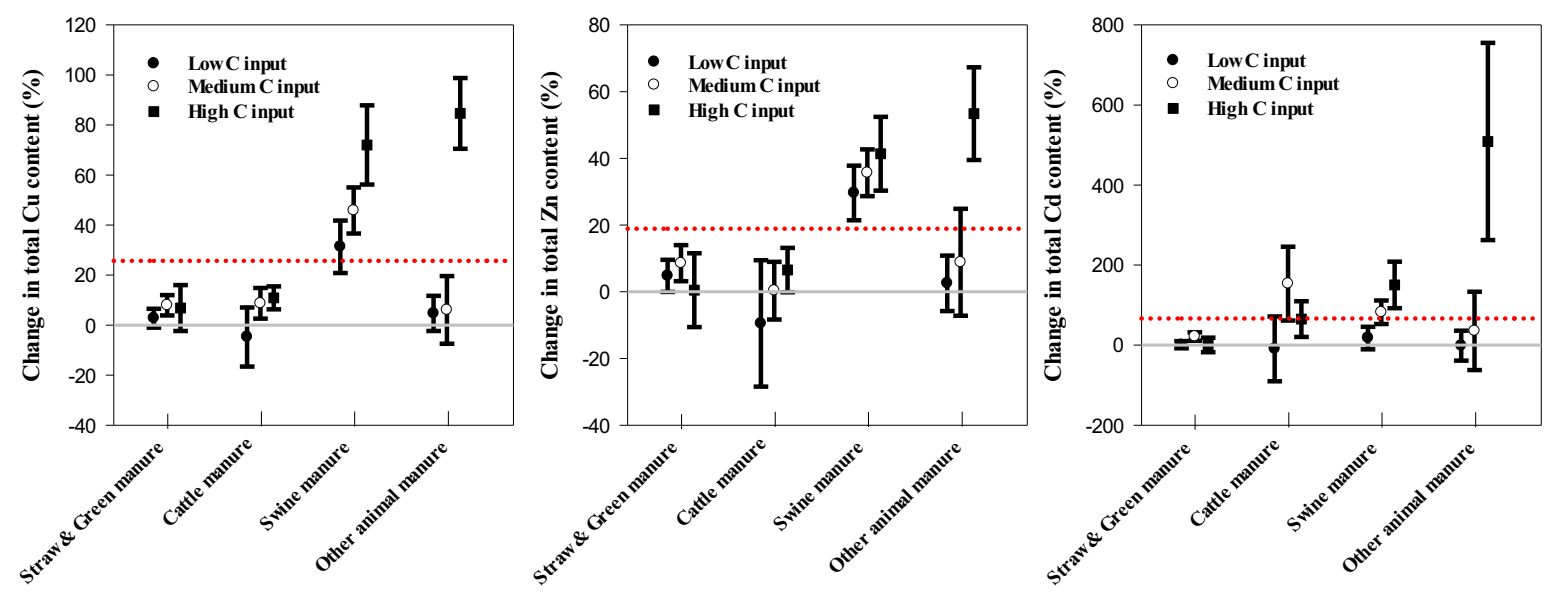

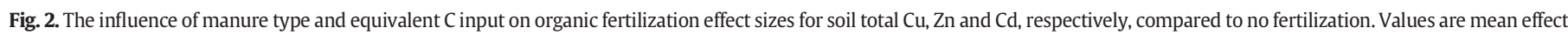
sizes with $95 \%$ confidence intervals. The dotted line indicates the cumulative effect size across all classes. 

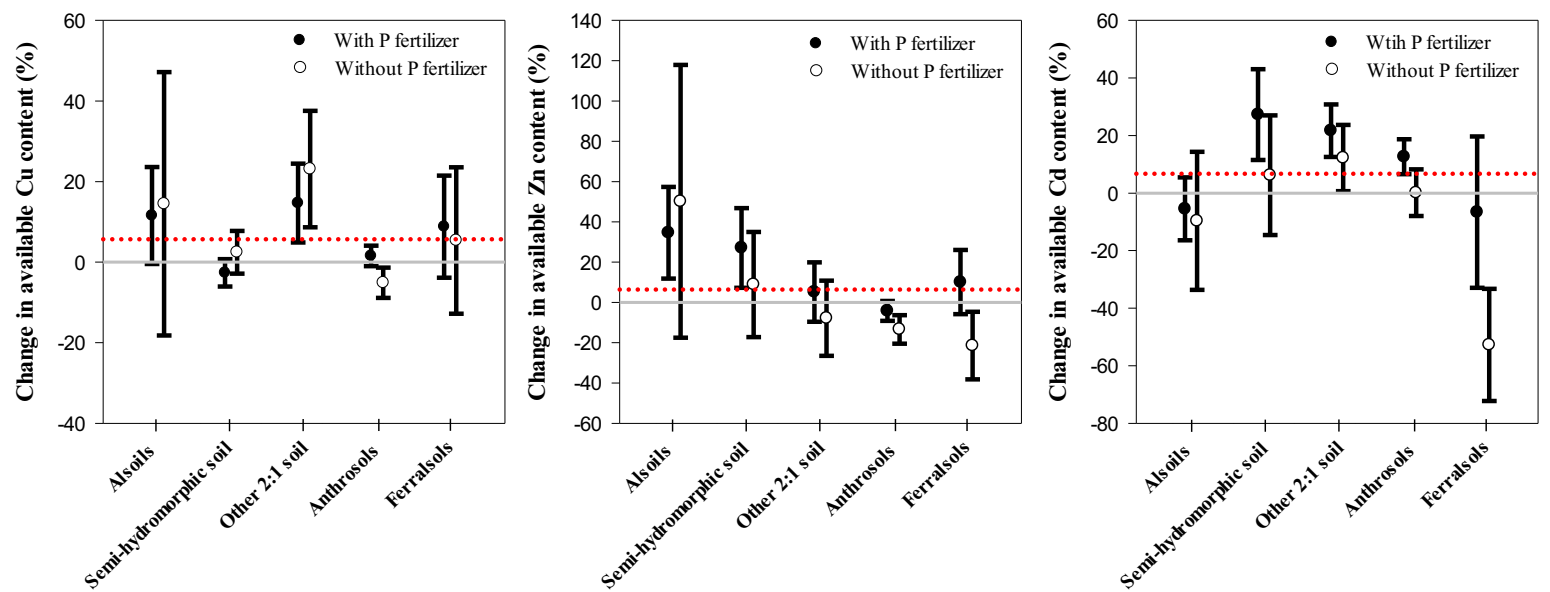

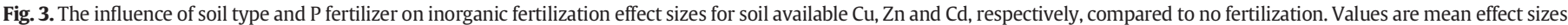
with $95 \%$ confidence intervals. The dotted line indicates the cumulative effect size across all classes.

3.3. Main factors explaining the variation of available PTTEs under longterm inorganic application

Although soil available $\mathrm{Cu}, \mathrm{Zn}$ and $\mathrm{Cd}$ increased slightly in response to inorganic fertilizer application, higher significant variation was also observed among different factors such as soil type, soil texture, temperature zone, location, land type, etc. (Tables S10-S11 and Fig. S5). The result of multivariate meta-regression showed that soil type contributed most to the heterogeneity, because it was the only significant variable explaining $15.11 \%$ variability in soil available $\mathrm{Cu}$, and played a more important role in determining variation in soil available $\mathrm{Zn}$ and $\mathrm{Cd}$, explaining $14.38 \%$ and $13.43 \%$ of the variation, respectively, which was far higher than that of P fertilizer, another of the two only significant variables (2.47\% and 3.96\%, respectively) (Tables S12-S14).

Our data further showed that the increase in available PTTEs in some soil types (such as Alfisols, Semi-hydromorphic soils and other 2:1 soils) under P fertilization was significantly higher than the average effect sizes (Fig. 3). For example, available Cd in Semi-hydromorphic soils with P fertilization increased by $27 \%$ (13-44\%); whereas there was a slight but statistically insignificant increase in available $\mathrm{Cd}$ without $\mathrm{P}$ fertilization. So, one needs to be careful to apply inorganic fertilizers (in particular P fertilizers) to these soils.

\subsection{PTTE pollution in long-term organically fertilized soils}

There was a close linear relation between the response of available and total PTTEs to long-term (3-35 years) organic fertilization, with a slope of 3.68 for $\mathrm{Cu}, 11.15$ for $\mathrm{Zn}$, and 0.75 for $\mathrm{Cd}$, respectively (Fig. 4), indicating that the potential risk of $\mathrm{Cd}$ came from the nearsynchronous increase in total and available Cd in soils (up to 25 times higher), whereas Zn's risk exists in a 35-times increase in its availability. However, the box-plot showed that Cd pollution was the most serious in long-term organically fertilized soils, with $42.6 \%$ of total Cd and $47 \%$ of available Cd content exceeding the national standards (GB156182018 and DB35/T 859-2016) (Fig. 5). By contrast, Zn pollution was not serious, for the percentages exceeding the national standard limit were only $1.57 \%$ and $7.9 \%$, respectively. Moreover, it should be noted from Fig. 5 that long-term application of OFs resulted in much more PTTE pollution in acidic soils than in alkaline and neutral soils.

A stronger linear relation was observed between soil Cd accumulation and Cd inputs from OFs $\left(\mathrm{R}^{2}=0.81, p<0.0001\right)$ (Fig. 6). To ensure safe application of OFs to farmlands within the next 100 years, we proposed a threshold limit value of $1.0 \mathrm{mg} C \mathrm{Cd}$ per $\mathrm{kg}$ dry matter based on the linear relationship and the background and risk control values of soil Cd (0.097 and $0.3 \mathrm{mg} \mathrm{kg}^{-1}$, respectively) (Wei et al., 1991), where a conventional application rate of $380 \mathrm{~kg} \mathrm{~N} / \mathrm{ha} / \mathrm{yr}$ (20\% N was substituted by dry OFs having a $2.08 \%$ average $\mathrm{N}$ content) was used as the basis for calculation (NAESC, 1999; Saikia et al., 2015; Zhang et al., 2018). The recommended value was in excellent agreement with the EU permissible level in compost (Kulikowska et al., 2015), but much less than the limit value $\left(3 \mathrm{mg} \mathrm{kg}^{-1}\right)$ of the Chinese standard for OFs (NY 525-2012).

\section{Discussion}

\subsection{Risk of PTTE pollution of soils during long-term fertilization}

Fertilizers were responsible for only $6-9 \%$ of $\mathrm{Pb}$ inputs to Chinese croplands (Luo et al., 2009), where $\mathrm{Pb}$ accumulation in soils was probably just offset by its loss through crop harvesting. So, applying fertilizers
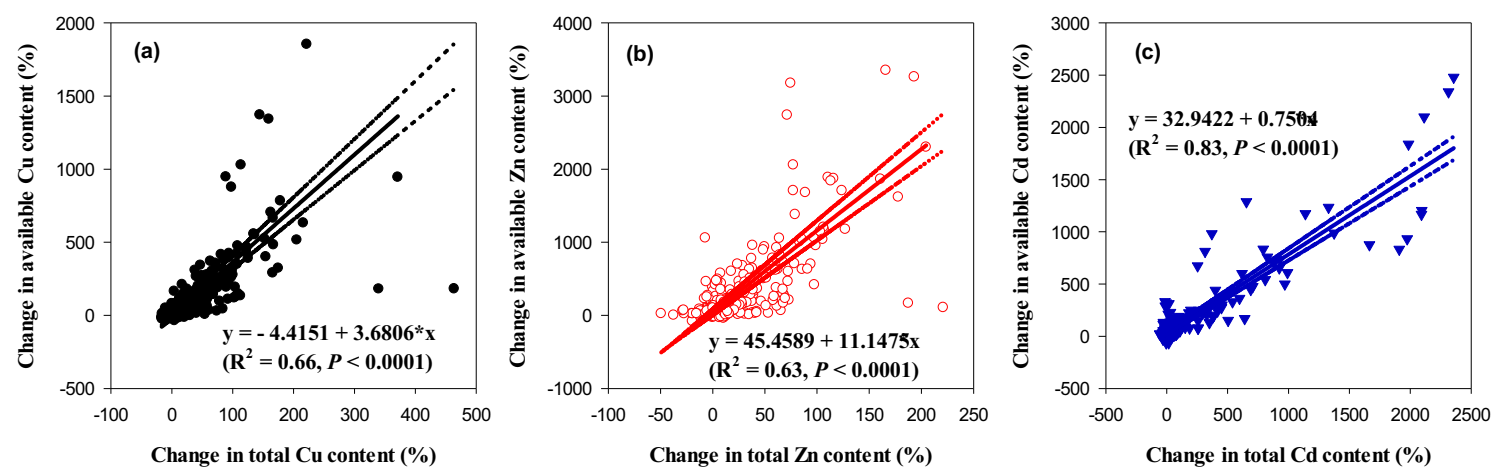

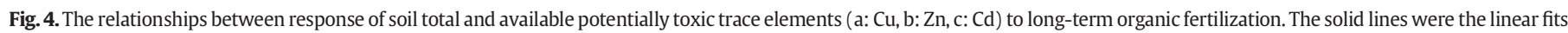
that best fitted the measurements, while the dotted lines were their $95 \%$ confidence intervals. 

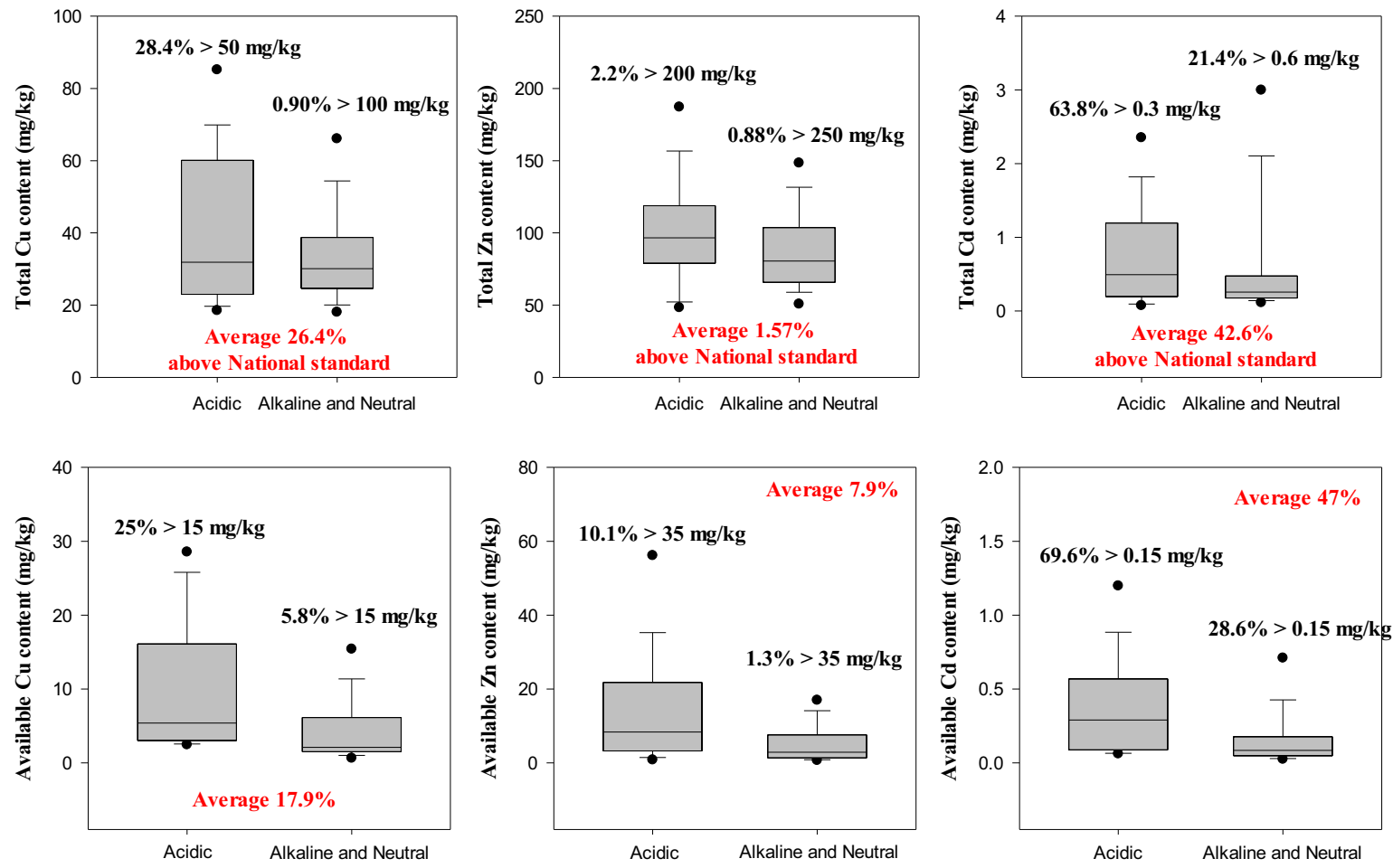

Fig. 5. Box-plot of total and available $\mathrm{Cu}, \mathrm{Zn}$ and $\mathrm{Cd}$ in long-term (3-35 years) organically fertilized soils.

did not contribute to $\mathrm{Pb}$ pollution. Similarly, PTTE input via inorganic fertilizers (in particular P fertilizers) in Chinese croplands was much less than in those of some other nations, where inorganic P fertilizer was responsible for only $1.7 \%$ of Cd inputs in China, whereas it contributed to $25.0 \%$ in England and Wales (Nicholson et al., 2003; Luo et al., 2009). Thus, it was considered that inorganic fertilizers (including P fertilizers) were not important pollution sources of PTTEs in Chinese croplands. The results were inconsistent with some researches in US and European countries, which showed that P-based fertilizers were likely to be the leading source of Cd soil pollution (Ali et al., 2020; Gupta et al., 2014; Nziguheba and Smolders, 2008). In conclusion, there is a low risk of PTTE pollution from long-term inorganic fertilizer application. However, the overuse of inorganic fertilizers had caused a decrease in soil $\mathrm{pH}$ (soil acidification), which potentially caused the increase in PTTE availability (Bolan et al., 2003; Wei et al., 2020). For example, P fertilization could increase available Cd in Semi-hydromorphic soils by $44 \%$ (Fig. 3). This means that reducing the application rate of $P$ fertilizers, or applying P fertilizers containing relatively small amounts of PTTEs, would be practical solutions for reducing the potential pollution risk in some soils (such as Alfisols, Semi-hydromorphic soils and other 2:1 soils).

The findings of this study revealed that inputs of PTTEs (especially Cd) from animal manure application are the main sources of PTTE pollution in agricultural soils, for their contribution to the inputs of $\mathrm{Cu}, \mathrm{Zn}$ and $\mathrm{Cd}$ to Chinese croplands were $68.5 \%, 51.0 \%$ and $54.9 \%$, respectively, significantly higher than that of inorganic fertilizers $(3.8 \%, 4.2 \%$ and $8.0 \%$, respectively) (Luo et al., 2009). Numerous studies have shown that the majority of PTTEs in feeds was excreted in feces and urine by livestock and poultry without being metabolized, which became a primary contributor to pollution in farmlands (Cang et al., 2004; Li et al.,

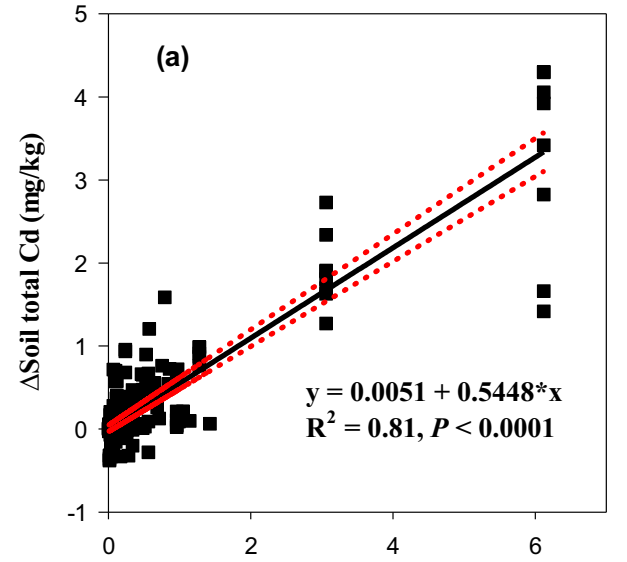

Accumulated Cd input by organic fertilizer (kg/ha)

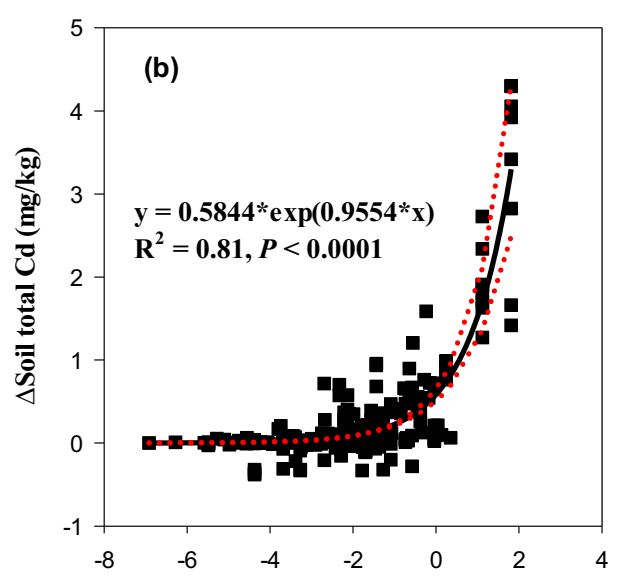

Ln[Accumulated Cd input by organic fertilizer (kg/ha)]

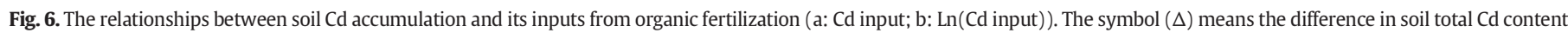
between organic fertilization treatment and control (no fertilization). Solid lines were the model fits, and dotted lines were the associated 95\% confidence intervals. 
2010; Li et al., 2019; Zhang et al., 2012; Wang et al., 2013). For example, Li et al. (2010) reported that higher residue of Cd in feeds $\left(31 \mathrm{mg} \mathrm{kg}^{-1}\right.$ ) resulted in higher levels of Cd in manures $\left(129.8 \mathrm{mg} \mathrm{kg}^{-1}\right)$, more than 430 times higher than China's maximum permissible limit of $\mathrm{Cd}$ in OFs (NY 525-2012). Hance, much effort should be devoted to stopping the adding PTTEs to feeds and feed additives.

In particular, it should be noted that long-term organic fertilization led to a significant increase in PTTE availability or RA in agricultural soils (Fig. 1 and Fig. S2). Obviously, this risk of PTTE pollution from applying OFs would substantially increase. Some researches have shown that DOM increased greatly after OF application due to its rapid decomposition, which would induce a prominent increase in available PTTEs (Antoniadis and Alloway, 2002; Laurent et al., 2020). To reduce the availability of toxic metals such as Cd in soils, some strategies for enhancing carbon sequestration efficiency (CSE) of OFs could be adopted.

\subsection{Strategies for safely applying OFs}

OFs have been highlighted as a major pollution source of $\mathrm{Cd}, \mathrm{Cu}$ and $\mathrm{Zn}$ in agricultural soils, contributing to approximately one-half of soil Cd pollution (42.6\% of total Cd and $47 \%$ of available Cd, respectively) (Fig. 5). Therefore, strategies with a focus towards reducing both metal content in OFs during the manufacturing processes and metal availability in soils during the decomposition of OFs must be developed. The following strategies have the potential to improve future OF application.

Firstly, we should pay attention to promoting straw and green manure return to field, or to implementing composting of various straw resources. They not only have low pollution risk potential to the surrounding environment (Fig. 2), but also show advantages in promoting soil fertility and thus offsetting partly the need for inorganic fertilizers and reducing PTTE availability in soils (Li et al., 2018). Secondly, laws and regulation were proposed to control $\mathrm{Cu}$ and $\mathrm{Zn}$ content in feeds and to forbid to specially add Cd to feeds and feed additives. $\mathrm{Cd}$ as an impurity is often present in $\mathrm{Zn}$-mineral supplements (such as zinc sulfate and phosphate, and $\mathrm{Zn}$ oxide). Thus, due to the abuse of $\mathrm{Zn}$-mineral additives to animal feeds for stimulating animal growth, higher residue of $\mathrm{Cd}$ in feeds and corresponding manure (31 $\mathrm{mg} \mathrm{kg}^{-1}$ and $129.8 \mathrm{mg} \mathrm{kg}^{-1}$, respectively) have been reported (Li et al., 2010). Meanwhile, the government should promote the utilization of natural feed additives and plant-derived products for livestock and poultry production. Finally, the nation needs to continue to advance SOM Improvement Project since 2005, because SOM played an important role in reducing available soil PTTEs (Karlsson et al., 2006; Ondrasek and Rengel, 2012). However, the increase in SOM is a very slow process, where the CSE of manures in Chinese croplands was as low as $9.6 \%$ so that SOM had an increase less than $5 \mathrm{~g} \mathrm{~kg}^{-1}$ during 30 years (Yang et al., 2017; Jiang et al., 2018). Therefore, more studies focusing on the improving CSE in China were needed.

\section{Conclusion}

The meta-analysis results showed that long-term organic fertilization resulted in serious potentially toxic trace element pollution (especially $\mathrm{Cd}$ ) in Chinese croplands, where more significant increase in available $\mathrm{Cu}, \mathrm{Zn}$ and $\mathrm{Cd}$ than in their total contents was found; whereas only a slight but significant increase in available $\mathrm{Cu}, \mathrm{Zn}$ and $\mathrm{Cd}$ was observed under long-term inorganic fertilization. Organic fertilizer type and application rate dominated the variation of potentially toxic trace elements, where animal manures such as swine and cattle manures containing Cd less than $1 \mathrm{mg} \mathrm{kg}^{-1}$ were recommended to be safely applied to agricultural soils. Soil type was main factor under long-term inorganic fertilization determining the variation of available potentially toxic trace elements, suggested that in some soils such as Alfisols and Semi-hydromorphic soils, lower amounts of P fertilizers or ones having small amounts of potentially toxic trace elements should be applied in order to reduce the potential pollution risk. In the organic fertilization practice, some strategies with a focus towards reducing the pollution risk must be developed, e.g., promoting straw return to field, forbidding $\mathrm{Cd}$ addition to feeds and feed additives, and improving carbon sequestration efficiency and thus soil organic matter. Overall, the findings of this study clearly gave a warning that organic fertilizer for the needs of agricultural production in China was not fully secured, and that governments, farmers and scientists needs to take timely measures to reduce its pollution risk.

\section{CRediT authorship contribution statement}

Shiwei Zhou: Conceptualization, Writing - original draft, Investigation, Validation, Writing - review \& editing. Shu Su: Formal analysis, Resources, Data curation, Validation, Writing - review \& editing. Ling Meng: Investigation, Validation, Writing - review \& editing. Xiao Liu: Formal analysis, Resources, Data curation, Validation, Writing - review \& editing. Hongyuan Zhang: Validation, Writing - review \& editing. Xiaoli Bi: Conceptualization, Writing - original draft, Investigation, Validation, Writing - review \& editing.

\section{Declaration of competing interest}

The authors declare no competing financial interests.

\section{Acknowledgements}

We thank all scientific research workers for their continuing efforts working on Chinese long-term field experiments. We would also like to thank all colleagues who participated in sample collection and analysis of soils and fertilizers, as well as all researchers whose data were used in this synthesis. We appreciate Prof. Minggang Xu and Prof. Wenju Zhang from Chinese Academy of Agricultural Sciences, Prof. Donald L. DeAngelis, Dr. Bo Zhang and Dr. Lu Zhai from University of Miami, and Prof. Dongmei Zhou from Nanjing University, for their valuable comments and suggestions on this study and writing.

This work was financially supported by National Natural Science Foundation of China (31870468, 31670471 and 41271254$)$, China Postdoctoral Science Foundation (2015M571179), and High-level Talent Project of Ludong University.

\section{Appendix A. Supplementary data}

Supplementary data to this article can be found online at https://doi. org/10.1016/j.scitotenv.2021.147967.

\section{References}

Ali, W., Mao, K., Zhang, H., Junaid, M., Xu, N., Rasool, A., Feng, X.B., Yang, Z.G., 2020. Comprehensive review of the basic chemical behaviours, sources, processes, and endpoints of trace element contamination in paddy soil-rice systems in rice-growing countries. J. Hazard. Mater. 397, 122720.

Antoniadis, V., Alloway, B.J., 2002. The role of dissolved organic carbon in the mobility of $\mathrm{Cd}, \mathrm{Ni}$ and $\mathrm{Zn}$ in sewage sludge-amended soils. Environ. Pollut. 117, 515-521.

Atafar, Z., Mesdaghinia, A., Nouri, J., Homaee, M., Yunesian, M., Ahmadimoghaddam, M., Mahvi, A.H., 2010. Effect of fertilizer application on soil heavy metal concentration. Environ. Monit. Assess. 160, 83-89.

Benke, M.B., Indraratne, S.P., Hao, X.Y., Chang, C., Goh, T.B., 2008. Trace element changes in soil after long-term cattle manure applications. J. Environ. Qual. 37, 798-807.

Bolan, N.S., Adriano, D.C., Curtin, D., 2003. Soil acidification and liming interactions with nutrient and heavy metal transformation and bioavailability. Adv. Agron. 78, 215-272.

Cang, L., Wang, Y.J., Zhou, D.M., Dong, Y.H., 2004. Heavy metals pollution in poultry and livestock feeds and manures under intensive farming in Jiangsu Province, China. J. Environ. Sci. 16, 371-374.

Dharma-Wardana, M.W.C., 2018. Fertilizer usage and cadmium in soils, crops and food. Environ. Geochem. Health 40, 2739-2759.

Food and Agriculture Organization of the United Nations (FAOSTAT). 2020. http://www. fao.org/faostat/en/\#data/QC (last update, June 15, 2020).

Godfray, H.C.J., Beddington, J.R., Crute, I.R., Haddad, L., Lawrence, D., Muir, J.F., Pretty, J., Robinson, S., Thomas, S.M., Toulmin, C., 2010. Food security: the challenge of feeding 9 billion people. Science 327, 812-818. 
Gupta, D.K., Chatterjee, S., Datta, S., Veer, V., Walther, C., 2014. Role of phosphate fertilizers in heavy metal uptake and detoxification of toxic metals. Chemosphere 108, $134-144$.

Hedges, L.V., Gurevitch, J., Curtis, P.S., 1999. The meta-analysis of response ratios in experimental ecology. Ecology 80, 1150-1156.

Hou, D.Y., O'Connor, D., Nathanail, P., Tian, L., Ma, Y., 2017. Integrated GIS and multivariate statistical analysis for regional scale assessment of heavy metal soil contamination: a critical review. Environ. Pollut. 231, 1188-1200.

Inaba, S., Takenaka, C., 2005. Changes in chemical species of copper added to brown forest soil in Japan. Water Air Soil Pollut. 162, 285-293.

Jiang, G.Y., Zhang, W.J., Xu, M.G., Kuzyakov, Y., Zhang, X.B., Wang, J.Z., Di, J.Y., Murphy, D.V., 2018. Manure and mineral fertilizer effects on crop yield and soil carbon sequestration: a meta-analysis and modeling across China. Global Biogeochem. Cycl. 32, 1659-1672.

Karalić, K., Lončarić, Z., Popović, B., Zebec, V., Kerovec, D., 2013. Liming effect on soil heavy metals availability. Poljoprivreda 19, 59-64.

Karlsson, T., Persson, P., Skyllberg, U., 2006. Complexation of copper (II) in organic soils and in dissolved organic matter-EXAFS evidence for chelate ring structures. Environ. Sci. Technol. 40, 2623-2628.

Kulikowska, D., Gusiatin, Z.M., Bułkowska, K., Klik, B., 2015. Feasibility of using humic substances from compost to remove heavy metals $(\mathrm{Cd}, \mathrm{Cu}, \mathrm{Ni}, \mathrm{Pb}, \mathrm{Zn})$ from contaminated soil aged for different periods of time. J. Hazard. Mater. 300, 882-891.

Laurent, C., Bravin, M.N., Crouzet, O., Pelosi, C., Tillard, E., Lecomte, P., Lamy, I., 2020. Increased soil $\mathrm{pH}$ and dissolved organic matter after a decade of organic fertilizer application mitigates copper and zinc availability despite contamination. Sci. Total Environ. 709, 135927.

Li, H., Dai, M.W., Dong, X.J., 2018. Current status and environment impact of direct straw return in China's cropland - a review. Ecotox. Environ. Safe. 159, 293-300.

Li, H., Yang, Z.L., Dai, M.W., Diao, X.Y., Dai, S.L., Fang, T., Dong, X.J., 2020. Input of Cd from agriculture phosphate fertilizer application in China during 2006-2016. Sci. Total Environ. 698, 134149.

Li, J., Xu, Y., Wang, L.G., Li, F.D., 2019. Heavy metal occurrence and risk assessment in dairy feeds and manures from the typical intensive dairy farms in China. Environ. Sci. Pollut. Res. 26, 6348-6358.

Li, Y.X., Xiong, X., Lin, C.Y., Zhang, F.S., Li, W., Han, W., 2010. Cadmium in animal production and its potential hazard on Beijing and Fuxin farmlands. J. Hazard. Mater. 177, 475-480.

Lindsay, W.L., Norvell, W.A., 1978. Development of a DTPA soil test for zinc, iron, manganese, and copper. Soil Sci. Soc. Am. J. 42, 421-428.

Liu, W.R., Zeng, D., Shi, L., Su, W.X., He, D.C., Wu, G.Y., Ma, X.R., Jiang, S., Jiang, C.H., Ying G.G., 2020. Comparisons of pollution characteristics, emission situations, and mass loads for heavy metals in the manures of different livestock and poultry in China. Sci. Total Environ. 734, 139023.

Luo, L., Ma, Y.B., Zhang, S.Z., Wei, D.P., Zhu, Y.G., 2009. An inventory of trace element inputs to agricultural soils in China. J. Environ. Manag. 90, 2524-2530.

Luo, Y.Q., Hui, D.F., Zhang, D.Q., 2006. Elevated $\mathrm{CO}_{2}$ stimulates net accumulations of carbon and nitrogen in land ecosystems: a meta-analysis. Ecology 87, 53-63.

Mortvedt, J.J., 1995. Heavy metal contaminants in inorganic and organic fertilizers. Fertil. Res. 43, 55-61.

National Agro-Tech Extension and Service Center (NAESC), 1999. National Nutrient Database for organic fertilizers in China. China Agriculture Press, Beijing (in Chinese).

Nicholson, F.A., Smith, S.R., Alloway, B.J., Carlton-Smith, C., Chambers, B.J., 2003. An inventory of heavy metals inputs to agricultural soils in England and Wales. Sci. Total Environ. 311, 205-219.

Novak, J.M., Watts, D.W., Stone, K.C., 2004. Copper and zinc accumulation, profile distribution, and crop removal in coastal plain soils receiving long-term, intensive applications of swine manure. Transactions of the ASAE 47, 1513-1522.

Nziguheba, G., Smolders, E., 2008. Inputs of trace elements in agricultural soils via phosphate fertilizers in European countries. Sci. Total Environ. 390, 53-57.

Ondrasek, G., Rengel, Z., 2012. The role of soil organic matter in trace element bioavailability and toxicity. In: Ahmad, P., Prasad, M. (Eds.), Abiotic Stress Responses in Plants. Springer, New York, pp. 403-423.
Ouyang, J.F., Liu, Z.R., Zhang, L., Wang, Y., Zhou, L.M., 2020. Analysis of influencing factors of heavy metals pollution in farmland-rice system around a uranium tailings dam. Process Saf. Environ. 139, 124-132.

Qian, J., Shan, X.Q., Wang, Z.J., Tu, Q., 1996. Distribution and plant availability of heavy metals in different particle-size fractions of soil. Sci. Total Environ. 187, 131-141.

Ramos, M.L., Moscuzza, C.H., Fernandez Cirelli, A., 2020. Total content and availability of micronutrients in soils and livestock manure. Rev. Int. Contam. Ambie. 36, 115-126.

Rao, Z.X., Huang, D.Y., Wu, J.S., Zhu, Q.H., Zhu, H.H., Xu, C., Xiong, J., Wang, H., Duan, M.M., 2018. Distribution and availability of cadmium in profile and aggregates of a paddy soil with 30-year fertilization and its impact on cd accumulation in rice plant. Environ. Pollut. 239, 198-204.

Saikia, P., Bhattacharya, S.S., Baruah, K.K., 2015. Organic substitution in fertilizer schedule: impacts on soil health, photosynthetic efficiency, yield and assimilation in wheat grown in alluvial soil. Agric. Ecosyst. Environ. 203, 102-109.

Sandroni, V., Smith, C.M.M., Donovan, A., 2003. Microwave digestion of sediment, soils and urban particulate matter for trace metal analysis. Talanta 60, 715-723.

Seufert, V., Ramankutty, N., Foley, J.A., 2012. Comparing the yields of organic and conventional agriculture. Nature 485, 229-232.

Shi, J.C., Yu, X.L., Zhang, M.K., Lu, S.G., Wu, W.H., Wu, J.J., Xu, J.M., 2011. Potential risks of copper, zinc, and cadmium pollution due to pig manure application in a soil-rice system under intensive farming: a case study of Nanhu, China. J. Environ. Qual. 40, $1695-1704$.

Su, S., Wang, Y., Liu, J., Zhu, P., Gao, H.J., Zhang, C.Y., Zhou, S.W., 2015. Evolution characteristics of heavy metals in the black soil under long-term fertilization. Sci. Agric. Sin. 48, 4837-4845 (in Chinese with English abstract).

Thompson, S.G., 2016. How to feed the world in 2050. http://www.fao.org/fileadmin/ templates/wsfs/docs/expert_paper/How_to_Feed_the_World_in_2050.pdf.

Thompson, S.G., Higgins, J.P.T., 2002. How should meta-regression analyses be undertaken and interpreted? Stat. Med. 21, 1559-1573.

Wang, H., Dong, Y.H., Yang, Y.Y., Toor, G.S., Zhang, X.M., 2013. Changes in heavy metal contents in animal feeds and manures in an intensive animal production region of China. J. Environ. Sci. 25, 2435-2442.

Wei, B.G., Yu, J.P., Cao, Z.Q., Meng, M., Yang, L.S., Chen, Q., 2020. The availability and accumulation of heavy metals in greenhouse soils associated with intensive fertilizer application. Int. J. Environ. Res. Public Health 17, 5359.

Wei, F.S., Chen, J.S., Wu, Y.Y., Zheng, C.J., 1991. Study on the background content on 61 elements of soils in China. Environ. Sci. 12, 12-19 (in Chinese with English abstract).

Wu, S.L., Feng, X.B., Wittmeier, A., 1997. Microwave digestion of plant and grain reference materials in nitric acid or a mixture of nitric acid and hydrogen peroxide for the determination of multi-elements by inductively coupled plasma mass spectrometry. J. Anal. Atom. Spectrom. 12, 797-806.

Yang, F., Xu, Y., Cui, Y., Meng, Y.D., Dong, Y., Li, R., Ma, Y.B., 2017. Variation of soil organic matter content in croplands of China over the last three decades. Acta Pedol. Sin. 54, 1047-1056 (in Chinese with English abstract).

Yu, H.X., Li, J., Luan, Y.N., 2018. Meta-analysis of soil mercury accumulation by vegetables. Sci. Rep. 8, 1261

Zhang, F.S., Li, Y.X., Yang, M., Li, W., 2012. Content of heavy metals in animal feeds and manures from farms of different scales in Northeast China. Int. J. Environ. Res. Public Health 9, 2658-2668.

Zhang, Y.T., Wang, H.Y., Lei, Q.L., Luo, J.F., Lindsey, S., Zhang, J.Z., Zhai, L.M., Wu, S.X., Zhang J.S., Liu, X.X., Ren, T.Z., Liu, H.B., 2018. Optimizing the nitrogen application rate for maize and wheat based on yield and environment on the Northern China Plain. Sci. Total Environ. 618, 1173-1183.

Zhou, S.W., Liu, J., Xu, M.G., Lv, J.L., Sun, N., 2015. Accumulation, availability, and uptake of heavy metals in a red soil after 22-year fertilization and cropping. Environ. Sci. Pollut. Res. 22, 15154-15163.

Zupancic, N., 2017. Influence of climate factors on soil heavy metal content in Slovenia. J. Soils Sediments 17, 1073-1083. 